\title{
Strategies for reducing the incidence of skin complications in newborns treated with whole-body hypothermia
}

\author{
Luca Filippi ${ }^{1}$, Serena Catarzi ${ }^{1}$, Letizia Padrini ${ }^{1}$, Patrizio Fiorini ${ }^{1}$, Giancarlo la Marca ${ }^{2}$, Renzo Guerrini ${ }^{3}$ \& \\ Gian Paolo Donzelli ${ }^{4}$
}

\begin{abstract}
${ }^{1}$ Neonatal Intensive Care Unit, Medical Surgical Feto-Neonatal Department, "A. Meyer" University Children's Hospital, Florence, Italy, ${ }^{2}$ Department of Pharmacology, University of Florence, Meyer Children's Hospital, Florence, Italy, ${ }^{3}$ Department of Neurology and Neurosurgery, "A. Meyer" University Children's Hospital, Florence, Italy, and ${ }^{4}$ Department of Sciences for Woman and Child's Health, University of Florence, Meyer Children's Hospital, Florence, Italy
\end{abstract}

Objective: To present the results of a strategy designed to reduce the incidence of skin complications in newborns with hypoxicischemic encephalopathy treated with moderate whole-body hypothermia. Design: Retrospective study. Setting: Neonatal Intensive Care Unit (NICU). Patients: Thirty-nine neonates cooled in the considered period. Intervention: Starting from January 2008 , for neonates treated with moderate whole-body hypothermia $\left(33.5^{\circ} \mathrm{C}\right)$, the cooling system was set in "automatic servo-controlled mode (ACM)", where the temperature of the circulating water could vary between $4{ }^{\circ} \mathrm{C}$ and $42^{\circ} \mathrm{C}$. Starting from January 2009, cooling blankets were used in another type of automatic mode, the "gradient variable mode (GVM)", where the circulating water was maintained at a specific pre-set gradient towards the patient's body temperature, and a specific nursing protocol (NP) was adopted. Measurements and main results: Two of the eleven newborns treated with the "ACM" exhibited skin complications compatible with subcutaneous fat necrosis (SFN). None of the twenty-eight newborns treated with the "GVM" exhibited skin complications. A comparison of the biochemical and hematological data between these two groups revealed that newborns treated after the adopting of a NP and the "GVM" showed lower serum protein C and calcium levels, and higher platelet levels. Conclusions: Our data suggest that newborns undergoing therapeutic cooling may benefit from a specific NP and correct cooling unit setting. Should further studies confirm our data, this nursing approach could be easily adopted.

Keywords: asphyxia, hypothermia, hypoxic-ischemic encephalopathy, newborn, subcutaneous fat necrosis

\section{Introduction}

Perinatal hypoxic-ischemic encephalopathy is still the single most important cause of serious brain injury in newborns. Recent trials have demonstrated that moderate hypothermia $(\mathrm{MH})$ (rectal or esophageal temperature $33-34{ }^{\circ} \mathrm{C}$ ) in asphyxiated neonates, if started within $6 \mathrm{~h}$ after birth and protracted for $72 \mathrm{~h}$, can significantly improve survival and reduce brain injury at 18 months [1]. Therefore, therapeutic hypothermia has recently been included in the Guidelines of International Consensus on Cardiopulmonary Resuscitation and Emergency Cardiovascular Care Science [2].

Cooling needs to be initiated as soon as possible after asphyxia [3]. MH can be started passively (by stopping the heating) or by applying ice bags to the head and body before and during transfer of the neonate to the referring hospital, where active $\mathrm{MH}$ can be obtained with selective head or whole-body cooling [3].

$\mathrm{MH}$ is generally well-tolerated. Side effects, represented by sinus bradycardia and thrombocytopenia, are transient and reversible with rewarming [4], Early studies suggested an increase in hypotension requiring inotrope infusion in newborns treated with hypothermia [4], but a subsequent analysis demonstrated that $\mathrm{MH}$ does not affect arterial blood pressure [5]. Moreover, several cases of subcutaneous fat necrosis (SFN) and cold panniculitis in newborns undergoing $\mathrm{MH}$ have recently been described [6-12]. A recent survey reported a prevalence of $\sim 1 \%$ among infants subjected to $\mathrm{MH}$ [13].

In this study, we report the onset of skin complications in two asphyxiated newborns treated with whole-body hypothermia, and illustrate the results of our strategy to reduce their incidence using a nursing protocol (NP) and a specific surface-cooling system adjustment. We analyzed the hypothesis that frequent mobilization of infants and the limiting of abrupt temperature changes of the water circulating in the mattresses might reduce the incidence of SFN and the inflammation markers.

\section{Materials and methods}

\section{Patients}

Starting from January 2008, asphyxiated newborns with gestational age $\geq 36$ weeks and birth weight $\geq 1,800$ g admitted to the 16-bed Neonatal Intensive Care Unit (NICU) of the A. Meyer University Children's Hospital were treated with moderate wholebody hypothermia when the following criteria were ascertained: (i) metabolic criteria: Apgar score $\leq 5$ at $10 \mathrm{~min}$, or persisting need for resuscitation, including endotracheal intubation or mask ventilation for more than $10 \mathrm{~min}$ after birth, or acidosis $(\mathrm{pH}$ $\leq 7.0$ and/or base deficit $\geq-16 \mathrm{mmol} / \mathrm{l}$ in umbilical cord blood or arterial, venous, or capillary blood) within $60 \mathrm{~min}$ after birth; (ii) neurological criteria: moderate to severe encephalopathy 
consisting of altered state of consciousness (irritability, lethargy, stupor, or coma) and $\geq 1$ of the following signs: hypotonia, or abnormal reflexes including oculomotor or pupillary abnormalities, absent or weak sucking, or clinical seizures. Cooling was started within $6 \mathrm{~h}$ after birth and maintained for $72 \mathrm{~h}$ at $33.5^{\circ} \mathrm{C}$. Newborns older than $6 \mathrm{~h}$ of age at the time of evaluation and newborns with major congenital abnormalities or evidence of encephalopathy other than hypoxic-ischemic encephalopathy were excluded. Neonates treated with deep hypothermia were also excluded from this study. Outborn patients were initially cooled to around $35{ }^{\circ} \mathrm{C}$ of core body temperature at their birth hospital, by stopping the heating or applying ice bags near head and body during transfer to the NICU.

Upon arrival, newborns were cooled to $33.5^{\circ} \mathrm{C}$ using a cooling blanket (Blanketrol ${ }^{\circledR}$ III, Hyper-hypothermia System; Cincinnati Sub-Zero, Cincinnati, $\mathrm{OH}$ ), connected by a servomechanism to an esophageal probe. Newborns were lying on this cooling blanket that was covered by a thin sheet. Rectal temperature was continuously monitored by a probe connected to a cardiomonitor (Infinity Delta; Dräger Medical System, Telford, PA) for simultaneous measurement of respiratory rate, heart rate, blood pressure, and oxygen saturation. Skin temperature was monitored with a skin probe on the abdominal wall by the radiant warmer thermal sensor or a temperature-monitoring unit (Mon-a-therm; Mallinckrodt Medical, St Louis, MO). After $72 \mathrm{~h}$ of hypothermia, newborns were gradually rewarmed to $36.5-37^{\circ} \mathrm{C}$ during the following 6-12 $\mathrm{h}$ by increasing the automatic control set-point of $0.5^{\circ} \mathrm{C}$ per hour. Newborns who complied with the entry criteria were enrolled until August 2009 in a pilot study for evaluating the safety of oral topiramate administration associated with hypothermia [14], and those admitted after February 2010 were enrolled in a randomized controlled study for evaluating the neuroprotective efficacy of combination treatment with topiramate and hypothermia [15].

\section{Surface-cooling system}

The cooling blanket unit used in our NICU can be set in manual control mode so that the operator can establish a priori the temperature of the circulating water, or in automatic mode, where the target temperature is reached with a servomechanism by heating or cooling the circulating water in relation to the newborn's rectal or esophageal temperature.

From January to December 2008, patients were cooled using the cooling blanket in automatic mode, called "auto control mode" (ACM). With this type of mode the operator sets the patient's target temperature $\left(33.5^{\circ} \mathrm{C}\right.$ according to our protocol); if the patient's actual temperature is lower than the target, the unit can heat the circulating water up to a maximum temperature of $42^{\circ} \mathrm{C}\left(107.6^{\circ} \mathrm{F}\right)$. Similarly, if the patient's actual temperature is higher than the target, the unit can cool the circulating water down by a minimum of $4^{\circ} \mathrm{C}\left(39.2^{\circ} \mathrm{F}\right)$. With this operating mode, the newborn's skin can be exposed to rapid and abrupt temperature changes. During this year two cases of SFN were observed.

Starting from January 2009 to December 2011, along with the application of the specific NP (see below) the cooling blanket was also used in another type of automatic mode, the so-called "gradient variable mode" (GVM) plus smart function. In this mode, after reaching the desired set-point temperature of $33.5^{\circ} \mathrm{C}$, the cooling blanket can be used to gradually control the patient's temperature by maintaining the circulating water temperature at a specific pre-set gradient towards the patient's body temperature. The objective was to expose the skin of newborns to slight temperature changes. In our unit a gradient of $5^{\circ} \mathrm{C}$ was chosen: meaning that the water can only be heated to $38.5^{\circ} \mathrm{C}\left(+5{ }^{\circ} \mathrm{C}\right)$ or cooled down to $28.5^{\circ} \mathrm{C}\left(-5^{\circ} \mathrm{C}\right)$. However, by activating the "smart" function, the water temperature gradient can be automatically increased by $5{ }^{\circ} \mathrm{C}$ every $30 \mathrm{~min}$ until achieving the target.

\section{NP}

From January to December 2008, newborns treated with $\mathrm{MH}$ were managed according to a nonspecific NP, which provided only sporadic turning of newborns to prevent bedsores. Starting from January 2009, all cooled newborns were subjected to a specific NP. This included the mobilization of neonates with alternating pronation and supination every $3 \mathrm{~h}$ during cooling in order to avoid prolonged contact of a specific skin area with the cooling surface.

\section{Study design}

We retrospectively compared biochemical parameters and the incidence of adverse skin effects between the two groups of hypothermic newborns treated with different cooling blanket modes and different NPs. The following blood tests were foreseen at $\mathrm{T}_{0}$ (time zero, when cooling was initiated), $\mathrm{T}_{24}, \mathrm{~T}_{48}, \mathrm{~T}_{72}$, and $24 \mathrm{~h}$ after the rewarming process $\left(\mathrm{T}_{96}\right)$ as planned in previous prospective studies $[14,15]$ : blood gas analysis (corrected for body temperature), lactate, glucose, serum electrolyte level (sodium, potassium, chloride, calcium), liver (aspartate and alanine aminotransferase, total protein, coagulation tests) and renal function tests (blood urea nitrogen, creatinine), creatine-kinase, creatine-kinase $\mathrm{MB}$ isoenzyme, complete cell blood count, and C-reactive protein (CRP) level. These laboratory tests were planned.

Skin injuries were recorded via retrospective analyses of medical and nursing records of patients treated with hypothermia, and with photographic documentation. Skin injuries were considered device-related when they were in contact with a cooling blanket, and not present at the time of hospital admission.

For newborns with SFN, a weekly or biweekly monitoring of total and ionized calcium levels was planned for at least 6 months or until the fat necrosis resolved.

\section{Statistical analysis}

The primary endpoint was the incidence of skin injury. The secondary endpoint was the different incidence of biochemical abnormalities between newborns treated with different nursing approaches. Differences in means between the cohorts were analyzed using the two-tailed Student's $t$-test, with significance recognized at the $P<0.05$ level.

The pilot study and the randomized controlled study regarding hypothermia $[14,15]$ were approved by the local ethics committees. Written informed consent was obtained from both parents of all enrolled newborns. Consent to show the photographs of the two infants with SFN was obtained from their parents.

\section{Results}

During this period, thirty-six newborns admitted to our NICU for perinatal asphyxia met the admission criteria and were treated with whole-body hypothermia. All the newborns were cooled during transfer to the NICU, by stopping the heating; no one was cooled applying ice bags. Eleven newborns were treated using the ACM and twenty-eight neonates were cooled with the GVM plus the specific NP. Demographic data of these newborns are shown in Table I. Infant's core temperatures were similar between the two groups during cooling (Figure 1a). Also mean blanket temperature was similar in both groups, but its fluctuation was significantly higher in the ACM group (Figure 1b). 
Table I. Demographic data of newborns treated with whole-body hypothermia.

\begin{tabular}{|c|c|c|c|}
\hline & $\begin{array}{c}\text { Newborns } \\
\text { treated with the } \\
\text { ACM } \\
(n=11)\end{array}$ & $\begin{array}{c}\text { Newborns treated } \\
\text { with GVM plus } \\
\text { specific NP } \\
(n=28)\end{array}$ & $P$ \\
\hline Male, $n(\%)$ & $6(54.5)$ & $19(67.9)$ & 0.449 \\
\hline $\begin{array}{l}\text { Gestational age } \\
\text { (weeks), mean } \pm \mathrm{SD}^{\mathrm{a}}\end{array}$ & $39.4 \pm 1.7$ & $38.2 \pm 2.8$ & 0.235 \\
\hline $\begin{array}{l}\text { Birth weight }(\mathrm{g}) \text {, } \\
\text { mean } \pm \mathrm{SD}\end{array}$ & $3,249 \pm 656$ & $3,102 \pm 468$ & 0.450 \\
\hline Cesarean section, $n(\%)$ & $7(63.6 \%)$ & $16(57.1 \%)$ & 0.719 \\
\hline $\begin{array}{l}\text { Stained amniotic fluid, } \\
n(\%)\end{array}$ & $7(63.6 \%)$ & $12(42.9 \%)$ & 0.295 \\
\hline Outborn, $n(\%)$ & $11(100.0 \%)$ & $28(100.0 \%)$ & N/A \\
\hline $\begin{array}{l}\text { Apgar score }(1 \mathrm{~min}) \text {, } \\
\text { mean } \pm \mathrm{SD}\end{array}$ & $2.4 \pm 2.1$ & $2.0 \pm 2.0$ & 0.493 \\
\hline $\begin{array}{l}\text { Apgar score }(5 \mathrm{~min}) \text {, } \\
\text { mean } \pm \mathrm{SD}\end{array}$ & $3.9 \pm 2.7$ & $4.1 \pm 2.2$ & 0.803 \\
\hline Crib score, mean \pm SD & $4.4 \pm 2.1$ & $3.8 \pm 2.0$ & 0.493 \\
\hline Arterial pH,mean \pm SD & $6.90 \pm 0.18$ & $6.84 \pm 0.16$ & 0.310 \\
\hline Arterial $\mathrm{BE}$, mean $\pm \mathrm{SD}$ & $-19.5 \pm 5.9$ & $-22.5 \pm 7.5$ & 0.256 \\
\hline $\begin{array}{l}\text { Arterial lactic acid } \\
(\mathrm{mmol} / \mathrm{l}), \text { mean } \pm \mathrm{SD}\end{array}$ & $15.0 \pm 4.7$ & $16.3 \pm 4.5$ & 0.526 \\
\hline $\begin{array}{l}\text { Hour hypothermia } \\
\text { beginning, mean } \pm \text { SD }\end{array}$ & $3.6 \pm 1.2$ & $3.6 \pm 1.4$ & 0.978 \\
\hline $\begin{array}{l}\text { Subcutaneous fat } \\
\text { necrosis, } n(\%)\end{array}$ & $2(18.2)$ & $0(0.0)$ & 0.014 \\
\hline
\end{tabular}

ACM, auto control mode; BE, base excess; GVM, gradient variable mode; N/A, not applicable NP, nursing protocol.

${ }^{a}$ Calculated from maternal menstrual history, obstetrical data or by Ballard's score.
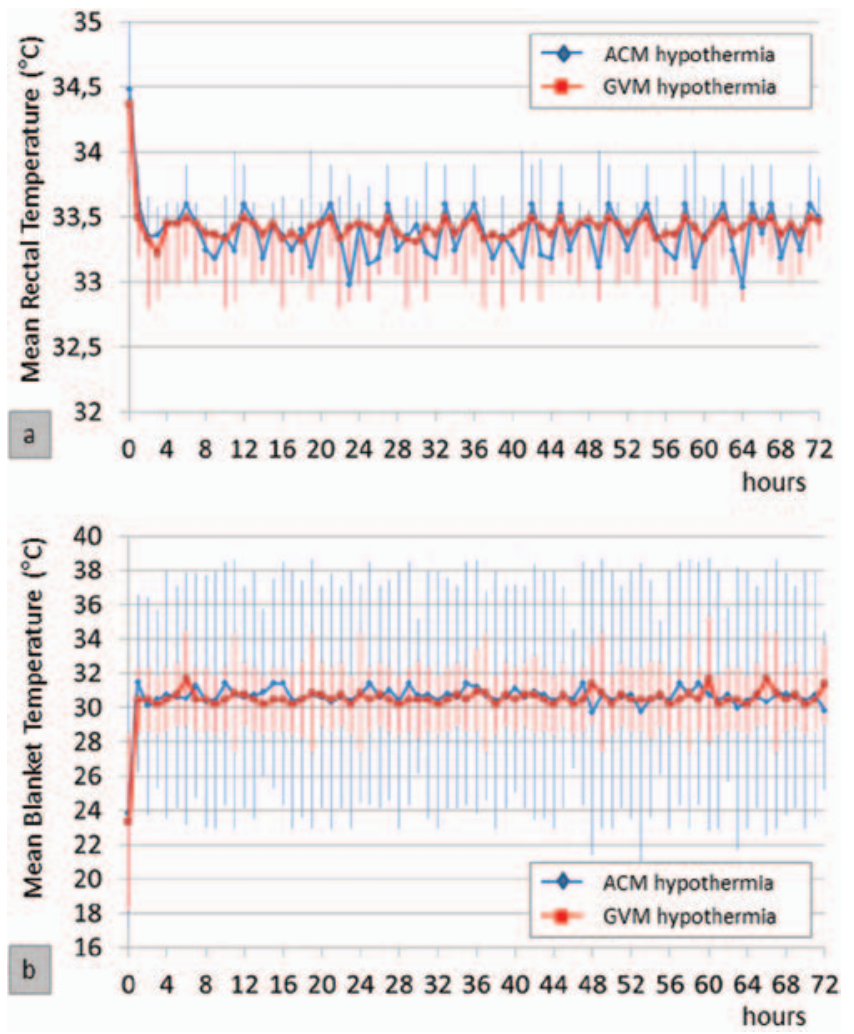

Figure 1. Mean rectal and blanket temperature in both groups. (a)Mean rectal temperatures and (b) mean blanket temperature in newborns treated with ACM or GVM hypothermia during the 72-h intervention period. The vertical bars indicate SD. ACM, auto control mode; GVM, gradient variable mode.
Within the group of newborns treated with the ACM mode, two neonates developed skin complications.

\section{Patient 1}

A full-term male infant born by urgent cesarean section for placental abruption started hypothermia at $5 \mathrm{~h}$ of age. About 20 days after rewarming a nontender area of erythematous indurated plaques was observed on the lateral surface of the neck and back (Figure 2a). During the following days multiple indurated areas were palpable in the subcutaneous tissues of the trunk and arms. The skin over the indurated areas was bluish-purple. High levels of blood CRP (up to $15.2 \mathrm{mg} / \mathrm{dl}$; normal value $<0.5$ ), not accompanied by a concurrent rising of procalcitonin, were observed. Platelet count and calcium level remained within the normal range during hospitalization and over the following weeks. Plasma CRP levels returned to normal range in about 40 days; skin recovery was complete, without scarring.

\section{Patient 2}

A full-term female infant born by instrumental vaginal delivery with application of vacuum extractor due to meconium-stained amniotic fluid, started hypothermia at $2 \mathrm{~h}$ of age. About 7 days after rewarming, multiple and confluent areas of bluish-purple indurated plaques were initially observed on the back (Figure $2 b$ ), and later extended to the posterior surface of thighs and armpits. The buttocks, protected by the diaper, were not affected. Blood CRP increased to $9.2 \mathrm{mg} / \mathrm{dl}$, with normal levels of procalcitonin. Platelet count and calcium level were slightly reduced to $51 \cdot 10^{9} / \mathrm{L}$ after $72 \mathrm{~h}$ of hypothermia and $8.3 \mathrm{mg} / \mathrm{dl}$ after $48 \mathrm{~h}$, respectively; both parameters normalized in a few days. Plasma CRP levels returned to normal range in about 20 days; skin recovery was complete, without scarring.

No newborns developed skin lesions in the group treated with the GVM plus smart function associated with the adopting of a NP.

The statistical analysis of the measured biochemical variables showed no significant differences between the two groups before beginning hypothermia (Table II). During cooling, some variables became statistically different. After $48 \mathrm{~h}$ of hypothermia in the group of newborns treated with ACM, the CRP levels remained significantly higher until after $24 \mathrm{~h}$ of rewarming, after $24 \mathrm{~h}$ of hypothermia, the platelet count remained significantly lower until after $24 \mathrm{~h}$ of rewarming, and after $72 \mathrm{~h}$ of hypothermia, the calcium levels remained significantly higher until after $24 \mathrm{~h}$ of rewarming (Figure 3). These differences remained even when the data of the two newborns with SFN were excluded from the ACM group.

\section{Discussion}

SFN of the newborn is a rare, inflammatory, transient and selflimiting panniculitis typically present within the first few days or weeks of life with erythemato-violaceus, subcutaneous nodules or plaques, localized usually on the back, arms, buttocks, thighs or cheeks $[16,17]$. Although its pathogenesis is not fully known, it occurs almost exclusively in full-term or post-term neonates with normal size for dates or macrosomia. Most of these have an history of perinatal stress, local ischemia following trauma or pressure injury due to macrosomia and dystocic labor [17]. Maternal risk factors include gestational diabetes, preeclampsia, dyslipidemia, and maternal exposure to cocaine [18] or calcium antagonists [19] during pregnancy. However, other authors have recently suggested novel predisposing genetic risk factors, such as familial dyslipidemia or thrombophilia [16]. 

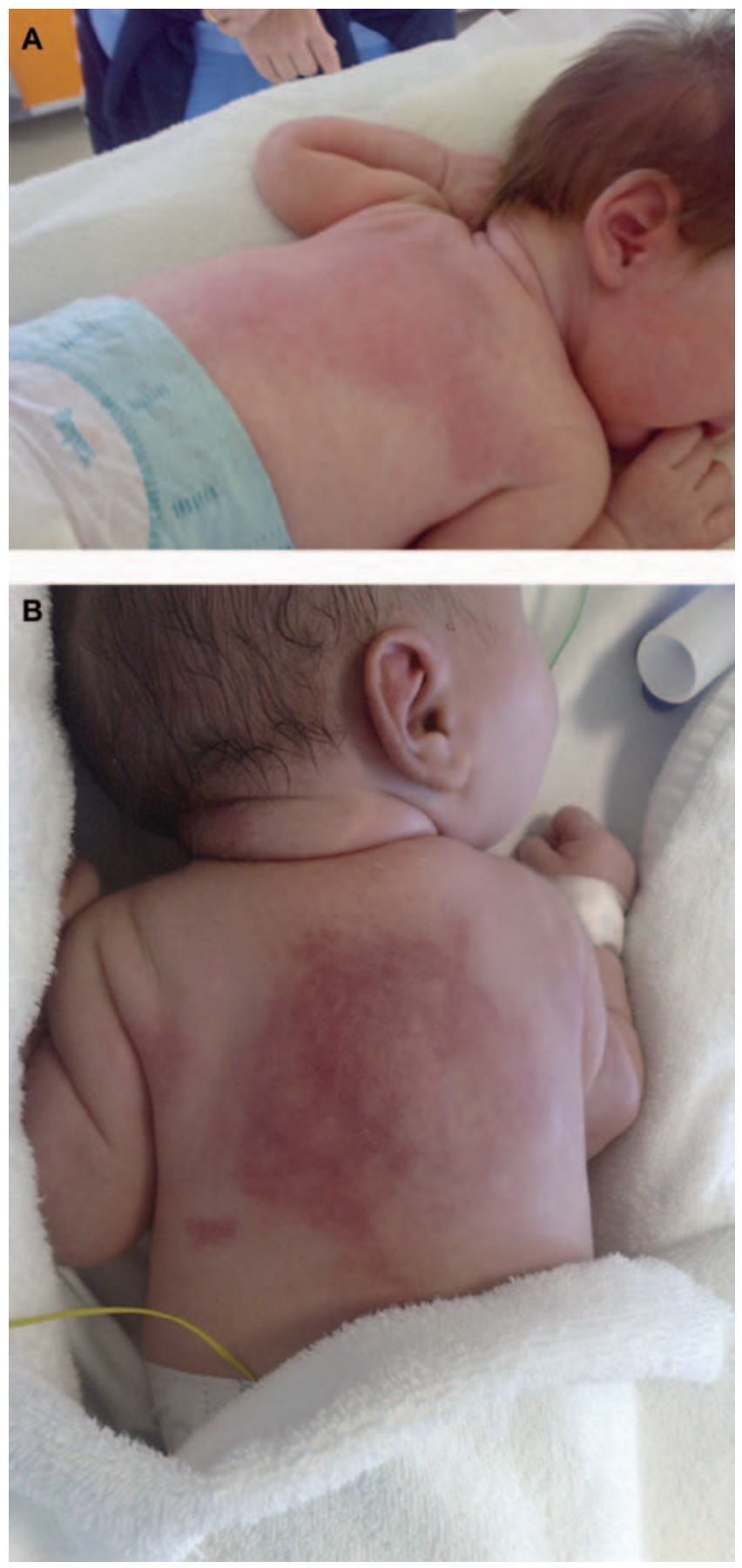

Figure 2. Subcutaneous fat necrosis. Erythematous and indurated plaques on the back of (a) patient 1 and (b) patient 2 after direct contact with the cooling blanket.

The high incidence of SFN in infants exposed to hypothermia has recently suggested that "cold stress" could play an important role in its pathogenesis [20]. SFN has been described in newborns following hypothermia when abandoned on the street [21] or exposed to cold weather [22]. Moreover, cases of SFN have been observed in newborns treated with applications of ice bags for supraventricular tachycardia [23-26], or subjected to wholebody cooling before being placed on cardiopulmonary bypass for cardiovascular surgery [27-30]. Neonates have an increased risk of developing SFN due to the different composition of fatty acid concentrations. It has been postulated that the higher percentage of the saturated to unsaturated fats ratio in the brown fat of newborns compared to the adult yellow fat of older children has an increased tendency to crystallize with hypothermic injury. In fact, the melting point of palmitic acid (the main saturated fatty acid) is around 63 ${ }^{\circ} \mathrm{C}$, significantly higher than the melting point of the oleic acid (the main unsaturated fatty acid) $\left(13^{\circ} \mathrm{C}\right)$. This difference could explain why a small decrease in the temperature of newborns may result in solidification and crystallization of their fat $[27,28,30]$.

More and more cases of SFN are currently being reported in infants treated with whole-body therapeutic hypothermia following perinatal asphyxia [6-13]. In infants cooled with ice bags and those treated with whole-body hypothermia using cooling blankets, skin lesions have been reported in areas subjected to contact with the surface of the cooling devices, as observed in both of our patients. Skin lesions have been reported in $\sim 20 \%$ of adult patients cooled with surface-cooling devices, even though only $6 \%$ were device-related [31]. These injuries were also more frequent in patients in shock-requiring vasopressors, or with a poor left ventricular ejection fraction, suggesting that cutaneous blood flow may play an important role [31]. In short, general ischemia after perinatal asphyxia and local ischemia after dystocic labor are both likely to play a key role in the development of SFN; however, skin-surface-cooling, inducing cutaneous and visceral vasoconstriction [32], may also lead to local ischemia and hypoxemia, thus causing the onset of SFN.

We hypothesized that wide and rapid changes of circulating water from cold to hot in cooling blanket, as observed mainly in newborns cooled with ACM hypothermia (Figure 1b), together with persistent pressure on the same skin regions, may compromise local perfusion, leading to local hypoxemia and subsequently putting these infants at risk of skin lesions. For these reasons we investigated the efficacy of our strategy, focusing on periodic mobilization and a gentler cooling blanket setting, in order to avoid abrupt temperature changes. Our experience is therefore very encouraging considering that after adopting this combined protocol the incidence of SFN was nil.

Nevertheless, this study has important limitations. First, the sample sizes are too small to draw statistically significant conclusions. This means that this study can only provide suggestions and recommendations for broader studies. Second, the patients studied had clinical features consistent with SFN, but they did not undergo biopsies or histological examinations necessary for differential diagnosis of cold panniculitis [23]. In fact, although both diseases may be clinically indistinguishable [24], their histopathologic findings are different [20]. This means that we can only draw the general conclusion that our protocol reduces the risk of skin damage. Third, the simultaneous introduction of a NP and a new cooling mode makes it difficult to determine which was the most effective procedure.

Even though SFN is usually a self-limiting disease that resolves within a few weeks or months without scarring, at times rare systemic complications including anemia, thrombocytopenia, hypoglycemia, hypertriglyceridemia, and hypercalcemia may occur [33]. Hypercalcemia, which has been reported to develop in approximately one-third of newborns with SFN [17] but also in over 50\% [16] is a very serious complication because it can also be fatal. It usually occurs between 2 and 16 weeks, when SFN begins to resolve and may either be asymptomatic or manifest with failure to thrive, lethargy, irritability, hypotonia, vomiting and, in severe cases, calcification of the soft tissues. Nephrolithiasis, nephrocalcinosis, renal failure, metastatic calcification in the pericardium and brain, and also cardiac arrest have been described [34-36]. Some authors reported an association with elevated prostaglandin levels that can lead to osteoclast activation and calcium release from granulomas or necrotic fat [37]. For others, hypercalcemia 
Table II. Blood parameters in infants cooled with auto control mode (ACM) or gradient variable mode (GVM) plus specific nursing protocol (NP).

\begin{tabular}{|c|c|c|c|c|c|c|}
\hline & & Pre & $24 \mathrm{~h}$ & $48 \mathrm{~h}$ & $72 \mathrm{~h}$ & $\begin{array}{c}24-\mathrm{h} \\
\text { post-rewarming }\end{array}$ \\
\hline \multirow[t]{2}{*}{$\mathrm{pH}\left(-\log \left[\mathrm{H}^{+}\right]\right)$} & $\mathrm{ACM}$ & $7.242 \pm 0.07$ & $7.338 \pm 0.07$ & $7.330 \pm 0.05$ & $7.362 \pm 0.09$ & $7.391 \pm 0.07$ \\
\hline & GVM + NP & $7.209 \pm 0.11$ & $7.321 \pm 0.06$ & $7.328 \pm 0.06$ & $7.322 \pm 0.09$ & $7.383 \pm 0.05$ \\
\hline \multirow[t]{2}{*}{$\mathrm{PCO}_{2}(\mathrm{~mm} \mathrm{Hg})$} & $\mathrm{ACM}$ & $38.0 \pm 12.2$ & $45.7 \pm 10.1$ & $48.3 \pm 8.4$ & $44.5 \pm 9.4$ & $42.3 \pm 6.1$ \\
\hline & GVM + NP & $35.2 \pm 15.2$ & $43.2 \pm 7.4$ & $45.4 \pm 9.9$ & $47.8 \pm 12.5$ & $43.1 \pm 8.0$ \\
\hline \multirow[t]{2}{*}{$\mathrm{PO}_{2}(\mathrm{~mm} \mathrm{Hg})$} & $\mathrm{ACM}$ & $62.5 \pm 26.7$ & $70.6 \pm 32$ & $69.4 \pm 19.3$ & $91.7 \pm 22.6$ & $82.3 \pm 24.2$ \\
\hline & GVM + NP & $80.1 \pm 27.3$ & $79.5 \pm 22.1$ & $73.6 \pm 29.9$ & $78.0 \pm 31.2$ & $72.5 \pm 19.2$ \\
\hline \multirow[t]{2}{*}{$\mathrm{BE}(\mathrm{mmol} / \mathrm{l})$} & $\mathrm{ACM}$ & $-10.7 \pm 3.2$ & $-1.5 \pm 3.0$ & $-0.5 \pm 3.9$ & $-0.4 \pm 4.3$ & $0.8 \pm 4.4$ \\
\hline & GVM + NP & $-12.6 \pm 5.4$ & $-4.1 \pm 3.8$ & $-2.8 \pm 3.2$ & $-2.1 \pm 3.9$ & $0.1 \pm 3.6$ \\
\hline \multirow[t]{2}{*}{$\mathrm{HCO}_{3}(\mathrm{mmol} / \mathrm{l})$} & $\mathrm{ACM}$ & $16.0 \pm 2.4$ & $22.5 \pm 2.7$ & $23.4 \pm 3.0$ & $24.0 \pm 3.7$ & $25.0 \pm 3.7$ \\
\hline & GVM + NP & $15.5 \pm 4.1$ & $21.7 \pm 2.3$ & $22.6 \pm 2.8$ & $22.8 \pm 2.7$ & $24.3 \pm 3.2$ \\
\hline \multirow[t]{2}{*}{ Lactate (mmol/l) } & $\mathrm{ACM}$ & $9.5 \pm 5.3$ & $4.1 \pm 2.2$ & $2.6 \pm 1.3$ & $2.0 \pm 1.5$ & $1.8 \pm 0.8$ \\
\hline & $\mathrm{GVM}+\mathrm{NP}$ & $10.7 \pm 6.5$ & $4.0 \pm 3.3$ & $3.0 \pm 3.3$ & $1.9 \pm 1.4$ & $1.7 \pm 1.0$ \\
\hline \multirow[t]{2}{*}{ Glucose (mg/dl) } & $\mathrm{ACM}$ & $108 \pm 41$ & $83 \pm 23$ & $72 \pm 14$ & $68 \pm 16$ & $79 \pm 18$ \\
\hline & GVM + NP & $118 \pm 59$ & $92 \pm 28$ & $81 \pm 21$ & $82 \pm 21$ & $90 \pm 17$ \\
\hline \multirow[t]{2}{*}{$\mathrm{Na}(\mathrm{mmol} / \mathrm{l})$} & $\mathrm{ACM}$ & $135 \pm 3.0$ & $134 \pm 4.3$ & $134 \pm 4.8$ & $136 \pm 3.5$ & $136 \pm 4.7$ \\
\hline & $\mathrm{GVM}+\mathrm{NP}$ & $135 \pm 5.0$ & $133 \pm 4.7$ & $132 \pm 5.1$ & $134 \pm 4.6$ & $137 \pm 5.1$ \\
\hline \multirow[t]{2}{*}{$\mathrm{K}(\mathrm{mmol} / \mathrm{l})$} & $\mathrm{ACM}$ & $4.3 \pm 0.8$ & $4.2 \pm 0.5$ & $4.1 \pm 0.7$ & $3.8 \pm 0.6$ & $3.7 \pm 0.7$ \\
\hline & GVM + NP & $4.0 \pm 0.5$ & $4.2 \pm 0.7$ & $4.3 \pm 0.9$ & $4.1 \pm 0.8$ & $3.7 \pm 0.6$ \\
\hline \multirow[t]{2}{*}{$\mathrm{Ca}(\mathrm{mg} / \mathrm{dl})$} & $\mathrm{ACM}$ & $9.0 \pm 1.3$ & $8.8 \pm 0.7$ & $8.7 \pm 0.7$ & $9.6 \pm 0.8^{*}$ & $9.5 \pm 0.7^{\star}$ \\
\hline & GVM + NP & $8.7 \pm 0.4$ & $8.7 \pm 0.7$ & $8.7 \pm 0.7$ & $8.7 \pm 0.8^{\star}$ & $8.6 \pm 0.9^{*}$ \\
\hline \multirow[t]{2}{*}{ Creatinine (mg/dl) } & $\mathrm{ACM}$ & $0.98 \pm 0.2$ & $0.95 \pm 0.3$ & $0.90 \pm 0.5$ & $0.85 \pm 0.5$ & $0.95 \pm 0.7$ \\
\hline & GVM + NP & $1.27 \pm 0.4$ & $1.17 \pm 0.4$ & $0.86 \pm 0.4$ & $0.76 \pm 0.3$ & $0.80 \pm 0.3$ \\
\hline \multirow[t]{2}{*}{ Urea nitrogen (mg/dl) } & $\mathrm{ACM}$ & $24.1 \pm 6.9$ & $27.8 \pm 9.7$ & $27.6 \pm 16.8$ & $31.1 \pm 20.7$ & $30.2 \pm 18.1$ \\
\hline & GVM + NP & $27.7 \pm 11.2$ & $35.8 \pm 12.9$ & $37.4 \pm 17.2$ & $34.6 \pm 17.9$ & $32.3 \pm 15.5$ \\
\hline \multirow[t]{2}{*}{ Aspartate aminotransferase (U/l) } & $\mathrm{ACM}$ & $140 \pm 78$ & $326 \pm 282$ & $133 \pm 73$ & $146 \pm 81$ & $70 \pm 41$ \\
\hline & $\mathrm{GVM}+\mathrm{NP}$ & $163 \pm 110$ & $153 \pm 148$ & $101 \pm 42$ & $76 \pm 35$ & $57 \pm 27$ \\
\hline \multirow[t]{2}{*}{ Alanine aminotransferase (U/l) } & $\mathrm{ACM}$ & $77 \pm 45$ & $121 \pm 57$ & $61 \pm 36$ & $87 \pm 21$ & $45 \pm 17$ \\
\hline & GVM + NP & $86 \pm 52$ & $101 \pm 68$ & $71 \pm 49$ & $75 \pm 35$ & $51 \pm 32$ \\
\hline \multirow[t]{2}{*}{ Total protein (g/dl) } & $\mathrm{ACM}$ & $5.3 \pm 1.3$ & $4.8 \pm 0.8$ & $4.9 \pm 0.7$ & $5.1 \pm 0.8$ & $5.2 \pm 0.7$ \\
\hline & GVM + NP & $5.7 \pm 0.5$ & $5.2 \pm 0.7$ & $5.2 \pm 0.6$ & $5.0 \pm 0.5$ & $5.2 \pm 0.6$ \\
\hline \multirow[t]{2}{*}{ Creatine-kinase (U/1) } & $\mathrm{ACM}$ & $1,488 \pm 839$ & $2,324 \pm 1,497$ & $1,286 \pm 997$ & $1,588 \pm 590$ & $326 \pm 150$ \\
\hline & $\mathrm{GVM}+\mathrm{NP}$ & $1,879 \pm 581$ & $1,667 \pm 978$ & $1,601 \pm 1,016$ & $1,575 \pm 787$ & $481 \pm 321$ \\
\hline \multirow[t]{2}{*}{ Creatine-kinase MB (U/l) } & $\mathrm{ACM}$ & $84 \pm 62$ & $69 \pm 42$ & $74 \pm 54$ & $74 \pm 41$ & $63 \pm 38$ \\
\hline & $\mathrm{GVM}+\mathrm{NP}$ & $69 \pm 42$ & $108 \pm 49$ & $104 \pm 80$ & $71 \pm 41$ & $63 \pm 34$ \\
\hline \multirow[t]{2}{*}{ Hemoglobin (g/dl) } & $\mathrm{ACM}$ & $15.1 \pm 5.5$ & $15.7 \pm 3.4$ & $14.9 \pm 3.0$ & $14.8 \pm 3.2$ & $13.3 \pm 2.6$ \\
\hline & GVM + NP & $16.3 \pm 2.3$ & $15.6 \pm 2.8$ & $14.8 \pm 2.6$ & $13.7 \pm 2.5$ & $12.1 \pm 2.6$ \\
\hline \multirow[t]{2}{*}{ White blood cell count $\left(10^{9} / 1\right)$} & $\mathrm{ACM}$ & $20.9 \pm 10.5$ & $11.9 \pm 4.4$ & $9.5 \pm 3.9$ & $7.9 \pm 3.8$ & $8.2 \pm 1.9$ \\
\hline & GVM + NP & $21.9 \pm 7.8$ & $14.5 \pm 4.7$ & $11.9 \pm 3.8$ & $8.8 \pm 2.3$ & $10.4 \pm 3.4$ \\
\hline \multirow[t]{2}{*}{ Platelet count $\left(10^{9} / 1\right)$} & $\mathrm{ACM}$ & $195 \pm 75$ & $154 \pm 60^{*}$ & $134 \pm 61^{*}$ & $116 \pm 69^{*}$ & $118 \pm 69^{*}$ \\
\hline & GVM + NP & $255 \pm 99$ & $232 \pm 82^{*}$ & $210 \pm 78^{\star}$ & $210 \pm 73^{*}$ & $261 \pm 98^{*}$ \\
\hline C-reactive protein (mg/l) & ACM & $1.3 \pm 2.7$ & $3.2 \pm 2.0$ & $5.3 \pm 3.8^{*}$ & $5.9 \pm 4.4^{\star}$ & $5.8 \pm 4.0^{\star}$ \\
\hline & GVM + NP & $0.6 \pm 1.5$ & $1.4 \pm 1.8$ & $2.3 \pm 2.1^{\star}$ & $3.3 \pm 2.3^{*}$ & $3.3 \pm 3.0^{*}$ \\
\hline Prothrombin time INR & $\mathrm{ACM}$ & $1.83 \pm 0.5$ & $1.86 \pm 0.5$ & $1.74 \pm 0.5$ & $1.46 \pm 0.4$ & $1.25 \pm 0.2$ \\
\hline & GVM + NP & $2.11 \pm 0.7$ & $1.75 \pm 0.5$ & $1.59 \pm 0.8$ & $1.30 \pm 0.3$ & $1.18 \pm 0.3$ \\
\hline Activated partial thromboplastin & $\mathrm{ACM}$ & $2.02 \pm 1.0$ & $1.98 \pm 0.6$ & $1.98 \pm 0.6$ & $1.92 \pm 0.6$ & $1.63 \pm 0.3$ \\
\hline time ratio & GVM + NP & $1.81 \pm 0.5$ & $1.65 \pm 0.4$ & $1.73 \pm 0.7$ & $1.59 \pm 0.6$ & $1.38 \pm 0.4$ \\
\hline Fibrinogen (mg/dl) & $\mathrm{ACM}$ & $219 \pm 72$ & $342 \pm 117$ & $368 \pm 161$ & $443 \pm 153$ & $490 \pm 220$ \\
\hline & GVM + NP & $234 \pm 76$ & $279 \pm 87$ & $319 \pm 106$ & $350 \pm 117$ & $415 \pm 117$ \\
\hline D-dimers (ng/ml) & $\mathrm{ACM}$ & $2,238 \pm 928$ & $1,069 \pm 874$ & $384 \pm 279$ & $288 \pm 208$ & $423 \pm 391$ \\
\hline & GVM + NP & $2,402 \pm 510$ & $649 \pm 478$ & $696 \pm 531$ & $729 \pm 690$ & $228 \pm 213$ \\
\hline
\end{tabular}

Mean \pm SD.

AVM, auto control mode; GVM, gradient variable mode; INR, international normalized ratio; NP, nursing protocol.

${ }^{\star} P<0.05$.

INR means International normalized ratio; BE means Base excess; MB is the name of the isoenzyme and it does not have to be expanded. 

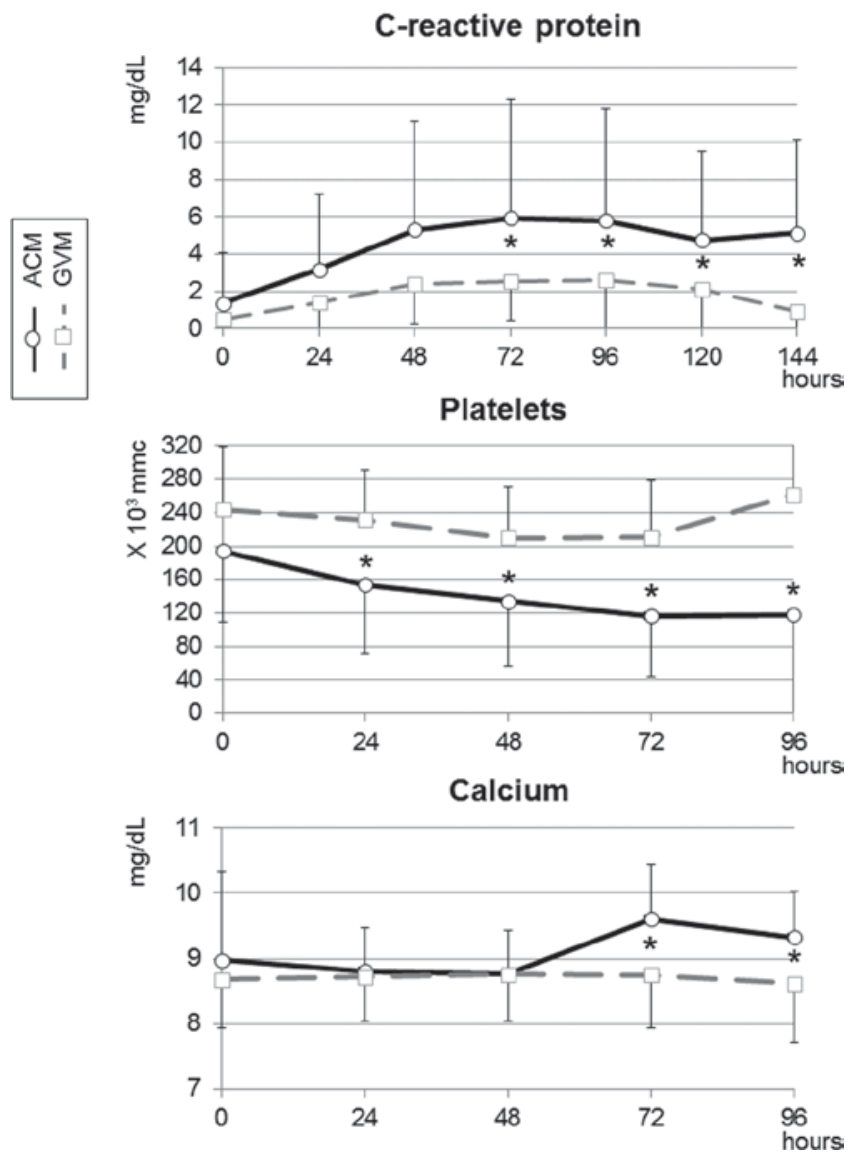

Figure 3. C-reactive protein level, platelet count, and calcium levels in hypothermic newborns treated with the "auto control mode" (ACM) or the "gradient variable mode" (GVM).

is believed to be caused by an excessive extra renal production of 1,25 -dihydroxyvitamin $\mathrm{D}[17,33,34,36,38]$ by the granulomatous macrophages, as observed in other granulomatous inflammations, such as sarcoidosis [39] which increases the intestinal calcium uptake [20].

These complications were not detected in our patients. However, the comparison of values of $\mathrm{C}$ protein and calcemia showed significantly higher values in the group of newborns treated with the ACM mode and the platelet count was significantly lower in this group. We cannot exclude a bias due to the small sample size; however, such data could suggest a more pronounced skin inflammation in the group of newborns exposed to abrupt changes of temperature, even if SFN was only observed in two neonates. This suggestion is supported by the observation that these differences continued between the two groups even after the exclusion of the two infants with SFN.

In conclusion, the lower incidence of skin injuries and lower CRP and serum calcium levels in newborns treated with the GVM mode increases the suspicion that rapid changes in temperature may be harmful to infants. Further studies are recommended to confirm the benefits of hypothermia obtained in a more gentle mode associated with a NP with periodic mobilization.

\section{Acknowledgment}

We are most grateful to the nursing staff of Neonatal Intensive Care Unit of A. Meyer University Children's Hospital, Florence, for their assistance in conducting this study.
Declaration of interest: The authors declared no conflicts of interest.

\section{References}

1. Edwards AD, Brocklehurst P, Gunn AJ, Halliday H, Juszczak E, Levene M, Strohm B, et al. Neurological outcomes at 18 months of age after moderate hypothermia for perinatal hypoxic ischaemic encephalopathy: synthesis and meta-analysis of trial data. BMJ 2010;340:c363.

2. Perlman JM, Wyllie J, Kattwinkel J, Atkins DL, Chameides L, Goldsmith JP, Guinsburg R, et al.; Neonatal Resuscitation Chapter Collaborators. Neonatal resuscitation: 2010 International Consensus on Cardiopulmonary Resuscitation and Emergency Cardiovascular Care Science with Treatment Recommendations. Pediatrics 2010;126:e1319-e1344.

3. Robertson NJ, Kendall GS, Thayyil S. Techniques for therapeutic hypothermia during transport and in hospital for perinatal asphyxial encephalopathy. Semin Fetal Neonatal Med 2010;15:276-286.

4. Jacobs S, Hunt R, Tarnow-Mordi W, Inder T, Davis P. Cooling for newborns with hypoxic ischaemic encephalopathy. Cochrane Database Syst Rev 2007:CD003311.

5. Battin MR, Thoresen M, Robinson E, Polin RA, Edwards AD, Gunn AJ; Cool Cap Trial Group. Does head cooling with mild systemic hypothermia affect requirement for blood pressure support? Pediatrics 2009;123:1031-1036.

6. Shankaran S, Laptook AR, Ehrenkranz RA, Tyson JE, McDonald SA, Donovan EF, Fanaroff AA, et al.; National Institute of Child Health and Human Development Neonatal Research Network. Whole-body hypothermia for neonates with hypoxic-ischemic encephalopathy. N Engl J Med 2005;353:1574-1584.

7. Duhn R, Schoen EJ, Siu M. Subcutaneous fat necrosis with extensive calcification after hypothermia in two newborn infants. Pediatrics 1968;41:661-664.

8. Zifman E, Mouler M, Eliakim A, Nemet D, Pomeranz A. Subcutaneous fat necrosis and hypercalcemia following therapeutic hypothermia-a patient report and review of the literature. J Pediatr Endocrinol Metab 2010;23:1185-1188.

9. Wiadrowski TP, Marshman G. Subcutaneous fat necrosis of the newborn following hypothermia and complicated by pain and hypercalcaemia. Australas J Dermatol 2001;42:207-210.

10. Oza V, Treat J, Cook N, Tetzlaff MT, Yan A. Subcutaneous fat necrosis as a complication of whole-body cooling for birth asphyxia. Arch Dermatol 2010;146:882-885.

11. Fumagalli M, Ramenghi LA, Pisoni S, Borzani I, Mosca F. Total body cooling: skin and renal complications. Arch Dis Child Fetal Neonatal Ed 2011;96:F377.

12. Gómez-Fernández C, Feito Rodríguez M, Collantes Bellido E, Ybarra Zabala M, de Lucas Laguna R. Indurated plaque on the back of a newborn after undergoing whole-body cooling. An Pediatr (Barc) 2011;74:64-66.

13. Strohm B, Hobson A, Brocklehurst P, Edwards AD, Azzopardi D; UK TOBY Cooling Register. Subcutaneous fat necrosis after moderate therapeutic hypothermia in neonates. Pediatrics 2011;128:e450-e452.

14. Filippi L, Poggi C, la Marca G, Furlanetto S, Fiorini P, Cavallaro G, Plantulli A, et al. Oral topiramate in neonates with hypoxic ischemic encephalopathy treated with hypothermia: a safety study. J Pediatr 2010;157:361-366.

15. Filippi L. Safety and Efficacy of Topiramate in Neonates With Hypoxic Ischemic Encephalopathy Treated With Hypothermia (NeoNATI) (NCT01241019). Available at: http://www. clinicaltrials.gov. Accessed October 2011.

16. Mahé E, Girszyn N, Hadj-Rabia S, Bodemer C, Hamel-Teillac D, De Prost Y. Subcutaneous fat necrosis of the newborn: a systematic evaluation of risk factors, clinical manifestations, complications and outcome of 16 children. Br J Dermatol 2007;156:709-715.

17. Burden AD, Krafchik BR. Subcutaneous fat necrosis of the newborn: a review of 11 cases. Pediatr Dermatol 1999;16:384-387.

18. Carraccio C, Papadimitriou J, Feinberg P. Subcutaneous fat necrosis of the newborn: link to maternal use of cocaine during pregnancy. Clin Pediatr (Phila) 1994;33:317-318.

19. Rosbotham JL, Johnson A, Haque KN, Holden CA. Painful subcutaneous fat necrosis of the newborn associated with intrapartum use of a calcium channel blocker. Clin Exp Dermatol $1998 ; 23: 19-21$. 
20. Polcari IC, Stein SL. Panniculitis in childhood. Dermatol Ther 2010;23:356-367.

21. Yimesel M, Assefa G. Extensive subcutaneous soft tissue calcification in a neonate following hypothermia: case report. East Afr Med J 2000;77:231-232.

22. Lee SK, Lee JH, Han CH, Ahn YM, Choi YS, Kim IO. Calcified subcutaneous fat necrosis induced by prolonged exposure to cold weather: a case report. Pediatr Radiol 2001;31:294-295.

23. Diamantis S, Bastek T, Groben P, Morrell D. Subcutaneous fat necrosis in a newborn following icebag application for treatment of supraventricular tachycardia. J Perinatol 2006;26:518-520.

24. Ter Poorten JC, Hebert AA, Ilkiw R. Cold panniculitis in a neonate. J Am Acad Dermatol 1995;33:383-385.

25. Mimouni F, Merlob P, Metzker A, Reisner SH. Supraventricular tachycardia: the icebag technique may be harmful in newborn infants. J Pediatr 1983;103:337.

26. Bolotin D, Duffy KL, Petronic-Rosic V, Rhee CJ, Myers PJ, Stein SL. Cold panniculitis following ice therapy for cardiac arrhythmia. Pediatr Dermatol 2011;28:192-194.

27. Collins HA, Stahlman M, Scott HW Jr. The occurrence of subcutaneous fat necrosis in an infant following induced hypothermia used as an adjuvant in cardiac surgery. Ann Surg 1953;138:880-885.

28. Chuang SD, Chiu HC, Chang CC. Subcutaneous fat necrosis of the newborn complicating hypothermic cardiac surgery. Br J Dermatol 1995;132:805-810.

29. Glover MT, Catterall MD, Atherton DJ. Subcutaneous fat necrosis in two infants after hypothermic cardiac surgery. Pediatr Dermatol $1991 ; 8: 210-212$
30. Silverman AK, Michels EH, Rasmussen JE. Subcutaneous fat necrosis in an infant, occurring after hypothermic cardiac surgery. Case report and analysis of etiologic factors. J Am Acad Dermatol 1986;15:331-336.

31. Jarrah S, Dziodzio J, Lord C, Fraser GL, Lucas L, Riker RR, Seder DB. Surface cooling after cardiac arrest: effectiveness, skin safety, and adverse events in routine clinical practice. Neurocrit Care 2011;14:382-388.

32. Wilson TE, Sauder CL, Kearney ML, Kuipers NT, Leuenberger UA, Monahan KD, Ray CA. Skin-surface cooling elicits peripheral and visceral vasoconstriction in humans. J Appl Physiol 2007;103:1257-1262.

33. Tran JT, Sheth AP. Complications of subcutaneous fat necrosis of the newborn: a case report and review of the literature. Pediatr Dermatol 2003;20:257-261.

34. Dudink J, Walther FJ, Beekman RP. Subcutaneous fat necrosis of the newborn: hypercalcaemia with hepatic and atrial myocardial calcification. Arch Dis Child Fetal Neonatal Ed 2003;88:F343-F345.

35. Aljaser F, Weinstein M. A 1-week-old newborn with hypercalcemia and palpable nodules: subcutaneous fat necrosis. CMAJ 2008;178:1653-1654

36. Nair S, Nair SG, Borade A, Ramakrishnan K. Hypercalcemia and metastatic calcification in a neonate with subcutaneous fat necrosis. Indian J Pediatr 2009;76:1155-1157.

37. Sharata H, Postellon DC, Hashimoto K. Subcutaneous fat necrosis, hypercalcemia, and prostaglandin E. Pediatr Dermatol 1995;12:43-47.

38. Kruse K, Irle U, Uhlig R. Elevated 1,25-dihydroxyvitamin D serum concentrations in infants with subcutaneous fat necrosis. J Pediatr 1993;122:460-463.

39. Farooque A, Moss C, Zehnder D, Hewison M, Shaw NJ. Expression of 25-hydroxyvitamin D3-1alpha-hydroxylase in subcutaneous fat necrosis. Br J Dermatol 2009;160:423-425. 